\title{
Envelhecimento e família: reflexões sobre a responsabilização familiar, os desafios às políticas sociais e a regulamentação da profissão de cuidador de pessoa idosa
}

\section{Aging and family: reflections on family accountability, challenges to social policies and regulation of the profession of caregiver for the elderly}

DOI: $10.46919 / \operatorname{archv1n3-003~}$

Recebimento dos originais: 10/03/2020

Aceitação para publicação: 10/04/2020

\section{Tatiana Enter Figueiredo}

Assistente Social Especialista em Atenção à Saúde da Pessoa Idosa pela Universidade Federal de Santa Catarina - UFSC

Endereço: Rua Orlando Linhares, 53 - Jardim Atlântico - Florianópolis/SC

E-mail: thatiana_figueiredo@msn.com

\section{RESUMO}

Este artigo trata das relações entre os cuidadores de pessoa idosa, a responsabilização da família nesse cuidado, as políticas sociais e a regulamentação da profissão de cuidador de pessoa idosa. A discussão leva em conta a crescente demanda de cuidadores e o atual processo de envelhecimento que deixou de significar apenas perdas e adoecimento, assim, a família e o Estado são demandados de diferentes formas para atender as intercorrências deste período.

Palavras-chave: Família, Envelhecimento, Política Social, Cuidador de Pessoa Idosa.

\begin{abstract}
This article deals with the relationship between the caregivers of the elderly, the accountability of the family in care, social policy and the regulation of the profession of elder caregiver. The discussion takes into account the growing demand for caregivers and the current aging process that ceased to mean only loss and illness, so the family and the state are demanded in different ways to meet the complications of this period.
\end{abstract}

Keywords: Family, Aging, Social Policy, Caregiver for Elderly.

\section{INTRODUÇÃO}

A intenção em abordar este tema implica questões decorrentes das mudanças no processo de envelhecimento e suas consequências, bem como, a necessidade da profissionalização dos cuidadores de pessoa idosa, demanda que tem estado em alta na sociedade brasileira. Alguns tipos de doenças degenerativas ou demências tem sido as grandes responsáveis pela necessidade de cuidados especializados na velhice. Daí a importância em refletirmos a respeito da complexidade que envolve o cuidado e os sujeitos responsáveis pela atividade, problematizando as questões que cercam essa ocupação e sua regulamentação como profissão. O número de famílias que tem se confrontado com as particularidades do envelhecimento e/ou adoecimento de um de seus membros, vem aumentando 
progressivamente. Diante do aumento indiscutível do envelhecimento das populações no mundo, realidade da qual o Brasil não fica alheio, nos fazem considerar que este processo requer medidas e serviços especializados de apoio social. Esse apoio pode incluir o acesso à informação, seja verbal ou escrita, através de material fornecido por pessoas ou grupos de apoio às famílias e aos cuidadores, como a oferta de serviços públicos e cursos profissionalizantes.

O aumento da expectativa de vida da população, fruto dos avanços da tecnologia e da medicina, é considerado uma conquista pela sociedade. Em consequência, há um aumento da parcela de idosos na população, acarretando mudanças no perfil das demandas por políticas públicas, pressionando o Estado, a sociedade e a família de diferentes formas. No que diz respeito à garantia das políticas sociais, é papel do Estado, juntamente com a sociedade e a família, prestar atendimento à pessoa idosa. Tal qual está assegurado nas legislações vigentes. Esta interação bem planejada, em torno de um objetivo comum, tende a resultar em um trabalho organizado, articulado e eficaz. A escassez de programas e a descontinuidade dos serviços pouco têm contribuído no enfretamento dessa realidade.

\section{FAMÍLIA E ENVELHECIMENTO}

Família é popularmente conhecida como o conjunto de pessoas que, com algum grau de parentesco, vivem na mesma residência e assim formam um lar. De acordo com Medeiros e Osório (2001, p. 06) "famílias são instituições com várias características, como laços de parentesco e normas de relacionamento que determinam direitos e obrigações de várias espécies a seus membros”. A família é uma instituição que, via de regra, possui grande valor em todas as camadas sociais tendo em vista que sua função principal é cuidar, zelar e proteger seus membros; entre outras responsabilidades. Com toda a carga social existente sobre o núcleo familiar, o Estado, no Brasil, de forma visível e significativa, se esquiva do compromisso e da responsabilidade com a proteção social da população.

Logo, a família, toma para si a responsabilidade pelos seus membros e, enfrenta uma série de consequências naturais da evolução do ser humano. Entre elas, destaca-se o envelhecimento e a atividade do cuidado com o idoso, doente ou não.

Dados do Instituto Brasileiro de Geografia e Estatística - IBGE ${ }^{1}$ mostram que no ano de 2009 havia cerca de 21 milhões de idosos no país e as principais causas para o aumento do envelhecimento eram resultados da baixa taxa de fecundidade e de mortalidade, nas décadas anteriores. Em 2000, outros relatos do IBGE revelam que 44\% das mulheres em idade reprodutiva tinham menos de dois filhos; e em $2006^{2}$, a taxa de fecundidade total (número médio de filhos que uma mulher teria ao final do seu período fértil) foi 2,0 filhos. Segundo a Síntese de Indicadores Sociais (2007), a queda da taxa de fecundidade nas

\footnotetext{
${ }^{1}$ Fonte: http://www1.ibge.gov.br/home/presidencia/noticias/noticia_visualiza.php?id_noticia=1717\&id_pagina=1

${ }^{2}$ Fonte: http://www.ibge.gov.br/ibgeteen/datas/mulher/mulherhoje.html
} 
décadas anteriores era uma tendência não só no Brasil, diversos países já atingiam valores bem abaixo do chamado nível de reposição natural da população, principalmente os europeus. O outro fator responsável foi a diminuição da taxa de mortalidade e isso se dá por conta da expectativa de vida das mulheres, que é maior do que dos homens. No ano 2000 a expectativa de vida feminina era de 7,6 anos a mais que a masculina.

\subsection{O CICLO VITAL DA FAMÍLIA E O ENVELHECIMENTO}

Com a mudança nos arranjos familiares e o desenvolvimento de novas perspectivas, a família inicia uma nova fase no seu ciclo vital. O envelhecimento, como processo multidimensional num todo, integra as mudanças associadas com a passagem do tempo e que, em muitos casos, alteram a capacitação funcional individual do idoso, sua personalidade, bem como a afetividade em relação aos familiares e ao meio em que vive. As alterações da estrutura familiar inerentes à última etapa do ciclo vital da família são caracterizadas por transições interligadas ao envelhecimento, como processo novo e único. A reconstrução relacional com as gerações mais novas, aliada às mudanças necessárias decorrentes do envelhecimento, constitui-se como desafios fundamentais às famílias nesta etapa do seu ciclo.

Sendo assim, o ciclo vital da família é uma sequência de transformações na organização familiar, ou seja, é a evolução histórica da família, onde as mudanças têm a ver com o desenvolvimento dos seus membros. No geral, a família desempenha dois papéis principais que caracterizam o ciclo vital, que são a função interna - proteção dos familiares que a compõem - e função externa, que é a socialização e transmissão de tradições e culturas. Quando a família assume o cuidado de uma pessoa idosa, ela encontra-se no ciclo fase madura ou fase última.

De acordo com Cerveny e Berthoud (1997, p.118):

$\mathrm{Na}$ fase de maturidade, adultos, pais e filhos desenvolvem suas interações, organizam e desorganizam, integram e desintegram, constroem e desconstroem padrões, normas, regras, valores e crenças familiares. Preenchem as lacunas de seu desenvolvimento com fatos que se perpetuam intergeracionalmente, transmitidos pelas lealdades de vínculos, afetos e sangue.

O envelhecimento representa essa última fase do ciclo vital, as relações familiares nessa fase serão marcadas por uma nova estruturação de papeis, com a saída de alguns integrantes e a inserção de novos. Essa intergeracionalidade representa o movimento da família, não sendo algo parado no tempo, mas circula entre o passado e o futuro, estando ligada num tempo histórico que sempre explica ao sujeito o seu estar em um grupo fundamental: a família.

Quando o envelhecimento passa ser visto como um problema, e para o idoso ter significado de morte, este se coloca ou acaba sendo colocado em uma posição negativa de sua existência; com isso, a perspectiva de presente e de futuro se fecha e faz nascer um sentimento de perda da própria existência. $\mathrm{O}$ 
processo do envelhecimento torna-se difícil quando a pessoa idosa é acometida de alguma doença crônica, grave ou degenerativa, com isso é necessário um cuidado intenso; pois a perda de autonomia para as atividades da vida diária, geralmente, é o primeiro fator a ser verificado. Quando isso ocorre, a família se vê, por incumbência das circunstâncias, obrigada a tomar as providências necessárias quanto aos procedimentos a serem definidos que nem sempre são os mais precisos ou cabíveis para o momento. Mas, sem auxílio e sem o respaldo do Estado, geralmente as famílias se veem abandonadas e sem apoio do setor público quando o assunto é cuidado familiar.

\begin{abstract}
Os estudos sobre o envelhecimento mostram que a saúde na velhice depende muito de hábitos de vida saudáveis e de cuidados que a pessoa recebeu ao longo de toda a vida, a partir da infância e até mesmo antes de nascer. Esses estudos permitem afirmar que velhice não é doença. No entanto, sabemos também, que as pessoas idosas são, em geral, mais vulneráveis, isto é, ficam mais sujeitas a adoecer e, quando adoecem, demoram mais para sarar. Esta é a razão por que o Brasil passou a realizar campanhas de vacinação contra a influenza (gripe) das pessoas de 60 anos e mais. Numa população envelhecida, isto é, onde há grande proporção de pessoas de 60 anos e mais, em relação aquelas que têm menos de 15 anos, há aumento de doenças crônicas, isto é, doenças que não tem cura, como pressão alta, diabetes, reumatismos, doenças do coração, do pulmão, do fígado, demência, câncer etc. que podem deixar marcas e complicações, levando a incapacidades, dependência, necessidade de cuidados de longa duração e instituições de longa permanência. (BORN, 2008 p. 113)
\end{abstract}

Sendo assim, conclui-se que superar os preconceitos e oferecer garantias de um envelhecimento mais pleno, satisfatório e com respeito, é obrigação de todos. Logo, é necessária uma reflexão sobre a própria velhice do indivíduo, bem como a construção de um futuro com vivência mais positiva, tranquila e facilitada. Afinal, pressupõe-se que será uma etapa a ser vivida por todos, e o indivíduo já em sua fase jovem deveria desenvolver um aprendizado constante, que vem junto com a experiência de vida e da fase adulta, para uma transição tranquila durante o processo de envelhecimento dentro do convívio familiar e da sociedade.

\title{
3 AS POLÍTICAS SOCIAIS, A FAMÍLIA E O CUIDADO
}

Como resultado do pluralismo de bem-estar, a família ganhou centralidade no debate sobre a produção do bem-estar no campo da política social. A função moral atribuída à família e a importância dada aos vínculos afetivos, naturaliza o cuidado como responsabilidade familiar eximindo o Estado dessa atribuição tão complexa nos sistemas de proteção social.

Historicamente a família sempre teve um papel importante no cuidado e na proteção dos membros que a compõem. Na atualidade ganhou uma atenção especial do Estado, mas ainda não tem o respaldo que merece. Quando o assunto é política social, a família é tida como provedora do bem-estar, como se ela se bastasse sem necessitar da assistência que tem direito; com isso há um estímulo de sua autonomia e uma redução de bens e serviços a seu dispor. Conforme Mioto, tal realidade “[...] vincula-se ao declínio 
da sociedade salarial e à crise do Welfare State, que fizeram com que a família fosse 'redescoberta', tanto como instância de proteção, como também possibilidade de 'recuperação e sustentação' de seus membros" (2008, p.130).

Se existe certo consenso de que as famílias necessitam de atenção social, quando colocamos em pauta os cuidados que lhes devem ser dirigidos, aparecem divergências que passam mesmo despercebidas. Na maioria das vezes, não nos damos conta de que, ao propormos e realizarmos ações de cuidados que envolvam as famílias, ou segmentos vulneráveis, colocamos em movimento diferentes formas de conceber a família e suas relações com outras esferas da sociedade, como Estado, trabalho e mercado. Das diferentes formas de concepção nascem diferentes modos de dirigir atenção aos grupos familiares e aos segmentos sociais vulneráveis. Por estes motivos, o tratamento do tema é complexo e extrapola o âmbito de uma discussão puramente operativa. (MIOTO, 2000, p.217)

Ao tratarmos das políticas públicas, a política social é a que ganha destaque, segundo o olhar do Serviço Social, política social pode ser compreendida como um conjunto de ações determinantes do Estado na formulação, execução e avaliação de programas, que visem estabelecer medidas de proteção social aos indivíduos, marcados pela exclusão econômica resultante do modelo de produção capitalista, ou mesmo dos múltiplos imprevistos do cotidiano. Toda política social deve ser voltada para os trabalhadores e àqueles que estão à margem sofrendo as consequências do sistema instituído. Assim, tanto o poder público como a sociedade devem se convencer de que cabe ao Estado a tarefa de organizar a política social do ponto de vista que funcione, e não como uma ação filantrópica. Cabe às políticas públicas garantir os direitos fundamentais como habitação, renda, alimentação, saúde, educação e segurança e também desenvolver programas voltados às necessidades específicas a determinado tipo de população atendida.

Aos poucos o Estado diminui sua carga de responsabilidades com as demandas sociais, ressurgindo a família como alternativa no processo de proteção das vulnerabilidades. Tratando-se de uma unidade econômica voluntária, espera-se que a família possa dar conta da reprodução e proteção dos membros que a compõem.

\subsection{O CUIDADO E O CUIDADOR}

A definição corrente para o verbo cuidar é: cautela, precaução, zelo, atenção, desvelo. Quando se trata de envelhecimento, o cuidado é algo ainda maior, pois é na realidade atitude de preocupação, ocupação, responsabilização e envolvimento afetivo. O cuidado embora sendo uma prática que faz parte da história é algo recente, cuidar é uma atividade que vai além do atendimento às necessidades do ser humano no momento que se encontra doente. O cuidado aparece quando alguém próximo necessita dele, e por sua natureza é uma atitude de atenção e carinho, ao mesmo tempo em que é uma preocupação e 
inquietação, pois o cuidador sente-se afetivamente envolvido e cria uma forte ligação com quem cuida. Isso se intensifica quando o cuidador faz parte diretamente da família.

As questões relacionadas ao cuidado com o idoso em domicilio são sempre mais complexas e de grande importância. A compreensão da pessoa idosa como pessoa única que está inserida em um contexto familiar e social com o qual mantêm contato de forma continuada deve ser sempre levada em consideração quando o cuidado é domiciliar. Deve-se levar em consideração a autonomia, a independência do idoso, assim como, sua capacidade para o desempenho de atividades rotineiras e sua vontade de ficar em determinado espaço, quando este ainda tem lucidez para isso.

Atualmente rompeu-se com essa visão de isolamento. Hoje o cuidado é visto como uma questão de saúde e assistência produzindo uma revalorização do ambiente familiar, onde o bem-estar da pessoa cuidada é a priori o principal objetivo das políticas públicas e da família.

O Ministério da Saúde, em 2008, elaborou o Guia Prático do Cuidador, com o objetivo de orientar cuidadores na atenção à saúde de qualquer faixa etária e também esclarecer os pontos mais comuns no cuidado domiciliar, acentuando a responsabilização da família, assim sendo conceitua duas categorias de cuidadores, a seguir apresentamos a definição de ambos:

Cuidador Informal: é o membro familiar, esposa(o), filha(o), irmã(ão), nora, normalmente do sexo feminino, que é 'escolhido' entre os familiares por ter melhor relacionamento ou intimidade com a pessoa idosa e por apresentar maior disponibilidade de tempo. Inclui-se neste grupo uma amiga ou vizinha, que mesmo não tendo laços de parentesco, cuida da pessoa idosa, sem receber pagamento, como voluntária. (BORN, 2008 p.54)

Cuidador Formal: é o profissional, que recebeu um treinamento específico para a função, exerce a atividade de cuidador mediante uma remuneração, mantendo vínculos contratuais. Ele pode ser contratado para exercer suas funções na residência de uma família, em Instituições de Longa Permanência para Idosos (ILPI), ou acompanhar a pessoa idosa em sua permanência em Unidades de Saúde (hospitais/clínicas, etc.). (BORN, 2008 p.54 e 55)

$\mathrm{O}$ ato de cuidar é muito complexo, pois, em certos momentos o cuidador informal é tomado por sentimentos diversos, como raiva, culpa, medo, angustia, confusão, cansaço. Tais sentimentos podem ser simultâneos e devem ser compreendidos pelos que cercam o cuidador, pois faz parte da relação entre ele e a pessoa cuidada. Quando um cuidador está disponível somente para esse fim, a carga sobre ele poder ser muito significativa, sendo muito importante haver opções de lazer e outras atividades, mesmo que voltadas as necessidades emanadas pelo idoso.

De um modo geral, as pessoas encarregadas do cuidado e suas famílias tem pouco preparo para administrar essa situação. A ajuda de profissionais especializados é primordial na determinação do bemestar do idoso, o preparo profissional e pessoal dos indivíduos relacionados ao cuidado é hoje uma 
necessidade crescente em muitos países, tendo um aumento significativo também em nosso país. O cuidador precisa colocar regras em sua rotina e impor um dia para cuidar de si, da sua saúde e do seu bem-estar. Pois, com o passar do tempo a pessoa cuidada, que normalmente se encontra doente, fica com a situação estável e a pessoa que o cuida adoece, é necessário que o cuidador tenha consciência da necessidade deste autocuidado e que se organize junto com os outros familiares e com sua agenda, para buscar aquilo que considera positivo para proporcionar-lhe benefícios físicos, mentais e emocionais.

Com toda essa situação que cerca o cuidador, atualmente há uma luta pela regulamentação dessa profissão, pois esse fator pode contribuir para a melhoria da atividade e a qualidade de vida dos cuidadores. Sendo um profissional regularizado, com direitos e um salário condizente com seus afazeres, muda o olhar sobre o cuidar, rompendo um pouco com os paradigmas fraternos e as obrigações familiares.

\section{O CUIDAdo COMO ÁREA PROFISSIONAL E A REGULAMENTAÇÃo DA PROFISSÃO DE CUIDADOR DE PESSOA IDOSA}

O Ministério da Saúde, através da Portaria n 2.029, de 24 de agosto de 2011, institui a Atenção Domiciliar no âmbito do Sistema Único de Saúde (SUS). A Atenção Domiciliar tem sido apresentada como alternativa ao cuidado hospitalar, possibilitando a retomada do domicílio como um espaço para produção do cuidado e despontando como um dispositivo para a produção da desinstitucionalização do cuidado, ao mesmo tempo, que transfere para a família essa responsabilidade. Vertentes sobre a Atenção Domiciliar problematiza a racionalização de recursos, valoriza a redução de custos por meio da substituição ou abreviação da internação hospitalar e destaca a reorientação do modelo tecno assistencial, apresentando a Atenção Domiciliar como um espaço potente na criação de novas formas de cuidar.

A Atenção Domiciliar expõe as equipes à realidade social na qual a família está inserida, à sua rotina, seus valores e às formas de cuidar instituídas no senso comum e na memória falada, passada de geração em geração. Um dos diferenciais das equipes de Atenção Domiciliar com relação às demais equipes de saúde, é o fato de que constroem sua relação com o sujeito que necessita de cuidados, no domicílio e não em um estabelecimento de saúde. O cuidador é o foco central das atribuições da equipe multiprofissional que irá oferecer assistência aos pacientes inseridos nessa perspectiva.

O Ministério da Saúde, através da Secretaria de Atenção à Saúde, em 2008, produziu o Guia Prático do Cuidador, que abrange os cuidados com pessoas no geral sejam elas crianças, jovens, adultos ou idosos e tem como foco os cuidados de saúde. Também no ano de 2008, a Secretaria Especial dos Direitos Humanos - Subsecretaria de Promoção e Defesa dos Direitos Humanos, produziu o Manual do Cuidador da Pessoa Idosa, com o objetivo de diminuir a violência e maus tratos contra a pessoa idosa, pois estudos demonstraram que, quanto menor o conhecimento o cuidador possui, menos paciência no 
cuidado e mais agressões são constatas. A capacitação do cuidador principal, seja ele informal ou formal, tornou-se uma necessidade gritante devido ao envelhecimento da população, o que passou a ser feito através da organização de cursos, que oferecem treinamentos em serviços de apoio às atividades da vida diária, de ajuda no processo saúde e doença, e de agir como fator facilitador da integração do idoso com a família e a sociedade. Através desta formação o cuidador principal terá condições de exercer com maior capacidade sua obrigação, favorecendo, desta forma, a melhoria da qualidade de vida das pessoas idosas.

A ocupação de cuidador de pessoa idosa é reconhecida pelo Ministério do Trabalho e Emprego (MTE) desde 2003, através da Classificação Brasileira de Ocupações (CBO). Conforme informações acessadas no Portal do Trabalho e Emprego do MTE, a estrutura básica da CBO foi elaborada em 1977, resultado do convênio firmado entre o Brasil e a Organização das Nações Unidas - ONU, por intermédio da Organização Internacional do Trabalho - OIT, tendo como base a Classificação Internacional Uniforme de Ocupações - CIUO datada de 1968. Desde a sua publicação, a CBO sofreu atualizações pontuais, sem modificações estruturais e metodológicas.

Mesmo com algumas conquistas, os direitos trabalhistas do cuidador de idosos passa por complicações, o motivo é, que enquanto não for aprovada a legislação própria e a regulamentação da profissão, que garanta os direitos específicos aos cuidadores de idosos, estes profissionais permanecem submetidos às normas gerais, comuns a todos os demais trabalhadores, as quais variam de acordo com a forma com que desempenham suas atividades e que tipo de acordo faz com a instituição ou com a pessoa que o contrata. Com isso deve primeiramente ser identificado o tipo de contrato de trabalho em que se enquadra o cuidador de idosos, seja empregado comum autônomo, doméstico ou voluntário (BORN, 2008).

Quanto ao processo de regulamentação da profissão, ainda está em andamento no Congresso Nacional o Projeto de Lei $n^{o}$ 284, de 2011, que dispõe sobre o exercício da profissão de Cuidador de Idosos. Esse Projeto de Lei foi de autoria do Senador Waldemir Moka do PMDB. Tal projeto de Lei, entre outras coisas, elenca as atribuições do profissional "cuidador de idoso"; define o que é instituição de longa permanência para idosos; estabelece que poderá exercer a profissão de cuidador de idoso o maior de 18 anos que tenha concluído o ensino fundamental e que tenha concluído, com aproveitamento, curso de cuidador de pessoa conferido por instituição de ensino reconhecida pelo Ministério da Educação; dispensa a exigência de conclusão de curso de cuidador as pessoas que, à época de entrada em vigor da presente Lei, venham exercendo a função há, pelo menos, dois anos; veda ao cuidador de idoso o desempenho de atividade que seja de competência de outras profissões da área de saúde legalmente regulamentadas.

Este Projeto de Lei está tramitando no Senado Federal desde o dia 25 de maio de 2011 quando foi apresentado, e desde então tem passado por diversas discussões e proposições de emendas, sendo a atual 
relatora a Senadora Marta Suplicy do PT. Em 05 de novembro de 2012, foi aprovado pelo Senado, estando a matéria aguardando aprovação na Câmara Federal dos Deputados.

Como vemos, o cuidador de pessoa idosa tem um trabalho mais domiciliar, porém não é empregado doméstico. Não tem como responsabilidade o cuidado da casa e sim da pessoa que necessita de cuidados. E como foi visto, têm funções claras e específicas e deve estar qualificado. A regulamentação da profissão de cuidador de pessoa idosa irá assegurar direitos e deveres como qualquer outro trabalhador assalariado.

\section{CONCLUSÃO}

Ao se tratar do assunto cuidado e família percebe-se que essa temática tem uma forte relação entre si, principalmente quando o assunto é o cuidado como responsabilidade das famílias. Observa-se no estudo realizado, que a família passou por diversas mudanças no decorrer da história, não somente em sua composição e na forma de conviver, mas também na maneira de exercer a proteção e o cuidado de seus membros. Pois, com o passar do tempo a família cada vez mais assume a incumbência de prover sozinha esse cuidado. As políticas sociais pouco estão fazendo para problematizar essa questão, pelo contrário, muitos programas têm estimulado o cuidado familiar e domiciliar. O papel principal do Estado no respaldo às famílias é o planejamento e a execução das políticas públicas, nesse caso a política social. As políticas públicas, em nosso país, ainda são excludentes e marginalizam as camadas mais pobres e carentes de nossa sociedade, onde muitos idosos se incluem. Esses necessitam de políticas na medida em que, ao permanecerem com suas famílias, dependem da ajuda de seus membros e, desta forma, faz-se necessária a criação de estratégias públicas de apoio para estes familiares para que possam ter condições de prestar os cuidados que a pessoa idosa necessita. A partir dessas reflexões, espera-se contribuir com as ações dos profissionais que rotineiramente se deparam com idosos que necessitam de cuidados e a realidade adversa de seus cuidadores, diante do desafio de reivindicarmos políticas públicas que protejam as famílias, não somente responsabilizando-as pelo bem-estar de seus componentes. 


\section{REFERÊNCIAS}

BORN, Tomiko. Cuidar Melhor e Evitar a Violência. Manual do Cuidador da Pessoa Idosa. Tomiko Born (org.) Brasília: Secretaria Especial de Direitos Humanos, Subsecretaria de Promoção e Defesa dos Direitos Humanos, 2008.

CERVENY, C. e BERThOUd, B. Família e Ciclo Vital. São Paulo: Casa do Psicólogo, 1997.

INSTITUTO BRASILEIRO DE GEOGRAFIA E ESTATISTICA (IBGE). Disponivel: http://www1.ibge.gov.br/home/presidencia/noticias/noticia_visualiza.php?id_noticia=1717\&id_pagina=1 Acesso em: 16 de novembro de 2012.

INSTITUTO BRASILEIRO DE GEOGRAFIA E ESTATISTICA (IBGE). Disponivel: http://www.ibge.gov.br/ibgeteen/datas/mulher/mulherhoje.html. Acesso em: 16 de novembro de 2012.

MEDEIROS, M.; OSÓRIO, R. Arranjos Domiciliares e Arranjos Nucleares no Brasil: classificação e evolução de 1977 a 1998. Texto para discussão n.788. Brasília: IPEA, 2001. (p.26-28) http://www.ipea.gov.br/pub/td/2001/td_0788.pdf. Acesso em: 13 de outubro de 2012.

MIOTO, R. C. T. Cuidados sociais dirigidos à família e segmentos sociais vulneráveis. In: Capacitação em Serviço Social e Política Social. Módulo 4 O trabalho do assistente social e as políticas sociais. Brasília: UnB, Centro de Educação Aberta, Continuada à Distância, 2000. p. 217-224

Família e Políticas Sociais. In: BOSCHETTI, I. et al. Política Social no Capitalismo: tendências contemporâneas. São Paulo: Cortez, 2008. p. 130-148. 